\title{
Developing symptom lists for people with cancer treated with targeted therapies
}

\section{Running heading: Targeted Therapy Symptom Lists}

Samantha C Sodergren ${ }^{1}$, Sally J Wheelwright ${ }^{1}$, Deborah Fitzsimmons ${ }^{2}$, Fabio Efficace ${ }^{3}$, Mirjam Sprangers ${ }^{4}$, Peter Fayers ${ }^{5}$, Amelie Harle ${ }^{6}$, Heike Schmidt ${ }^{7}$, Andrew Bottomley ${ }^{8}$., Anne-Sophie Darlington $^{1}$, Charlotte Benson ${ }^{9}$, Anne Bredart ${ }^{10}$, Leopold Hentschel ${ }^{11}$, Juan Ignacio Arraras, J.I. ${ }^{12}$, Georgios Ioannidis ${ }^{13}$, Michael Leahy ${ }^{14}$, Iwona Lugowska ${ }^{15}$, Ourania Nicolatou-Galitis ${ }^{16}$, Duska Petranovic ${ }^{17}$, Gudrun E Rohde ${ }^{18,19}$, Vasilis Vassiliou, ${ }^{20}$, Colin D Johnson ${ }^{21^{*}}$ On behalf of the EORTC Quality of Life Group

${ }^{*}$ Corresponding author

Address for correspondence: Professor Colin Johnson, Cancer Sciences, University of Southampton, Southampton, UK. c.d.johnson@soton.ac.uk

${ }^{1}$ School of Health Sciences, University of Southampton, Southampton, UK

${ }^{2}$ Public Health, Policy and Social Sciences, University of Swansea, Swansea, UK

${ }^{3}$ Italian Group for Adult Hematologic Disease (GIMEMA), Rome, Italy

${ }^{4}$ Department of Medical Psychology, Amsterdam University Medical Center, Amsterdam, The Netherlands

${ }^{5}$ Aberdeen University School of Medicine, Medical Science \& Nutrition, Aberdeen, UK

${ }^{6}$ Poole Hospital NHS Foundation Trust, Poole, UK

${ }^{7}$ Martin Luther University Halle-Wittenberg, Halle, Germany

${ }^{8}$ EORTC Quality of Life Department, Brussels, Belgium

${ }^{9}$ The Royal Marsden NHS Foundation Trust, Sutton, UK

${ }^{10}$ Institut Curie, Paris, France

${ }^{11}$ University Hospital Carl Gustav Carus, Dresden, Germany

${ }^{12}$ Complejo Hospitalario de Navarra, Navarra, Spain

${ }^{13}$ Nicosia General Hospital, Nicosia, Cyprus

${ }^{14}$ The Christie NHS Foundation Trust, Manchester, UK

${ }^{15}$ Maria Sklodowska-Curie Memorial Cancer Centre-Institute of Oncology, Warsaw, Poland

${ }^{16}$ National \& Kapodistrian University of Athens, Athens, Greece

${ }^{17}$ University Clinical Hospital Center Rijeka, Rijeka, Croatia 
18 Faculty of Health and Sport Sciences, University of Adger, Agder, Norway

${ }^{19}$ $\varnothing$ rlandet Hospital, Kristiansand, Norway

${ }^{20}$ Bank of Cyprus Oncology Centre, Nicosia. Cyprus

${ }^{21}$ Cancer Sciences, University of Southampton, Southampton, UK

\section{Acknowledgements}

We would like to express our gratitude to the patients and health care professionals who took part in this research project and shared their views and experiences. We would also like to acknowledge the support of staff at the collaborating centres.

\section{Declarations}

\section{Funding}

Funding for this work was awarded by the EORTC Quality of Life Group (QLG) (Reference Number 010 / 2010)

\section{Role of the Funding Source}

The QLG awarded funding in a competitive peer-reviewed grant application process. The executive Committee of the QLG reviewed and approved the final manuscript before submission for consideration, 'On behalf of the EORTC QLG'

\section{Conflict of Interests}

Juan Ignacio Arraras received funding from "la Caixa" Foundation (ID 1000010434), Caja Navarra Foundation and UNED Pamplona, under agreement LCF/PR/PR15/51100007

\section{Consent to Participate}

Ethical approval for this study was awarded for the Lead site (NRES Committee South Central Southampton B 11/SC/0412). Each collaborating centre also received their local approvals. All participants gave their informed consent to participate and for their anonymous data to be shared.

\section{Consent for Publication}

All authors and the EORTC QLG granted their permission for the publication of this manuscript.

\section{Availability of data and material}

Raw data generated from this work cannot be shared as permissions were not requested from participants. The symptom set generated from this work is available from the EORTC QLG upon request https://qol.eortc.org/questionnaires/

Code availability 
Not applicable

Authors Contributions

All authors contributed to the manuscript preparation, editing and review.

\section{Abstract}

\section{Background}

Targeted therapies (TTs) have revolutionised cancer treatment with their enhanced specificity of action. Compared with conventional therapies, TTs are delivered over a longer period and often have unusual symptom profiles. Patient reported outcome measures such as symptom side-effect lists need to be developed in a time-efficient manner to enable a rapid and full evaluation of new treatments and effective clinical management

\section{Objective}

The aim of this study is to develop a set of TT-related symptoms and identify the optimal method for developing symptom lists.

\section{Patients and Methods}

Symptoms from TT treatment in the context of Chronic Myeloid Leukaemia (CML), HER2 positive breast cancer, or Gastrointestinal Stromal Tumours (GIST) were identified through literature reviews, interviews with health care professionals (HCPs) and patients, and patient focus groups. The symptom set was then pilot tested in patients across the three cancer diagnoses: The number of items derived from each source (literature, patients, or HCPs) were compared. 
Results

A total of 316 patients and 86 HCPs from 16 countries participated. An initial set of 209 symptoms was reduced to 61 covering 12 symptom categories. Patient interviews made the greatest contribution to the item set.

\section{Conclusions}

Symptom lists should be created based on input from patients. The item set described will be applicable to the assessment of new TTs, and in monitoring treatment.

\section{Key Points}

Development of symptom measures needs to be rapid to respond to the ever-changing treatment landscape.

Symptom sets are a resource to create symptom lists in a time-efficient manner. The content of symptom lists should be informed by patient experience.

\section{Introduction}

Patient reported outcome (PRO) measures provide an assessment of a patient's health condition from the patient's perspective rather than relying on the interpretation of others, such as clinicians (1). In recent years there has been increased focus on PROs in clinical trials, clinical practice, and health technology assessments (2-5). The Food and Drug Administration (FDA) and the European Medicines Agency (EMA) recommend the use of PRO measures in marketing applications for new treatments $(2,4)$ and place emphasis on patient-reported symptoms. Symptom assessment enhances precision in describing the patient's symptom experience as well as monitoring treatment side-effect profiles (6). Online symptom reporting by patients with cancer can facilitate comprehensive symptom capture in real time, reduce costs and allow for timely detection and 
management of symptoms (7-9). This can translate into improved patient experience and outcome (10). The National Cancer Institute Common Terminology Criteria for Adverse Events (CTCAE) enables patients to report symptoms related to cancer and its treatment directly onto a trial database (11). Others have used a more flexible computer-adaptive testing approach to tailor symptom assessment according to patient relevance, and thus reduce respondent burden $(12,13)$. All these systems require the identification and/or construction of many items which can be labourintensive and costly.

Cancer- and treatment-related symptoms have a significant impact on health-related quality of life (HRQOL) and form an integral part of its definition and assessment. Symptom items feature strongly in HRQOL assessments. For example, 17 of 30 items in the widely used EORTC Quality of Life core cancer questionnaire, the EORTC QLQ-C30, refer to symptoms. However, symptom lists alone do not provide a full assessment of HRQOL, which includes the broader domains of physical, role, cognitive, emotional, and social functioning (14).

Targeted therapies (TTs) have revolutionised treatments of several cancers especially HER2 positive breast cancer (trastuzumab) (15), haematological malignancy such as Chronic Myeloid Leukaemia (CML) (16) , and Gastro Intestinal Stromal Tumours (GISTs) (imatinib) $(17,18)$, by substantially improving clinical outcomes since their approval towards the end of the last century and the early 2000s. TTs selectively target molecular agents involved in tumour growth and progression. Despite their selectivity, TTs cause a range of unexpected and unpredictable symptoms, such as rash and headache, rarely seen with traditional treatment. In our review of the literature on the side-effects of TTs used for GISTS, skin-related problems, particularly Hand-Foot syndrome associated with sunitinib, were reported in nearly half of the papers reviewed affecting $37 \%$ of patients in the randomised clinical trials and case reports reviewed (19). Furthermore, TTs are delivered for much 
longer than standard chemotherapy, with a longer exposure to potential side-effects. With longterm drug administration, low-grade side-effects may significantly interfere with patients' wellbeing and daily functioning and may be overlooked $(20,21)$. These unusual symptoms are likely to go undetected by HRQOL questionnaires developed before the widespread use of TTs.

In addition to the EORTC Quality of Life core cancer questionnaire, the EORTC Quality of Life Group (QLG) has developed a suite of questionnaires specific to different tumour or condition types using a rigorous and time-consuming process (22). A more flexible and dynamic approach has been proposed which recognises the need to keep pace with the ever-changing treatment landscape and includes symptom side-effect questions as an add-on to EORTC measures. (6). This strategy is facilitated by the EORTC QLG Item Library which includes nearly 1000 validated, multi-lingual items from the EORTC questionnaires $(23,24)$. Recent studies adopting this flexible approach include routine electronic monitoring of HRQOL in metastatic renal cell cancer, which used the EORTC QLQC30 with nine questions from the Item Library to assess common treatment-related symptoms (25) and a study of rare cancers in which 10 items were selected from the Item Library to supplement the EORTC QLQ-C30 (26).

The aim of the current study was to identify a symptom set for patients treated with TTs using the EORTC QLG Module Guidelines (22) and to use this process to inform recommendations for the optimal method for developing symptom lists across different patient groups.

\section{Methods}

The development process covered three phases: Phase 1: identification of symptoms to include in the item set, from systematic reviews of the literature, interviews with patients and health care professionals (HCPs) with experience of TTs and patient focus groups; Phase 2: selection of symptoms and creation of the item set; Phase 3: Pilot testing the item set in patients to ensure 
acceptability, comprehension and completeness of the set. Interviews were conducted in several countries and languages to ensure multi-cultural relevance.

\subsection{Tumour types and targeted therapies}

We recruited patients treated (either currently or previously) with TT for either CML, HER2 positive breast cancer, or GIST, cancer types in which TTs featured prominently within their treatment at the time of writing the protocol for this study. Given that different TTs are used to treat these cancers, it was anticipated that we would capture a broad range of symptoms. In addition, these cancer scenarios were chosen for pragmatic reasons with each one having a different starting point for the generation of the item set, explained below.

$\mathrm{CML}$ is a common haematological malignancy and TTs are now widely used in its treatment. Indeed, these therapies have remarkably improved survival of patients with CML (27). When the present study began, there was an EORTC CML-specific questionnaire in development (EORTC QLQ-CML24) (28). We therefore used the symptom data collected as part of that work (28) to inform the development of the item set.

Breast cancer is a common cancer, and was one of the first to benefit from TTs with the introduction of trastuzumab $(29,30)$. The development of the EORTC breast cancer module (EORTC QLQ-BR23) (31) was completed in 1996 before the advent of TTs.

GIST is a rare cancer which also responds well to TTs. Historically, in the context of advanced or unresectable GISTS, treatment options were limited. TTs such as imatinib have become the standard therapy (31), There is currently no GIST-specific EORTC module to assess the impact of GIST and its treatment on HRQOL .

\subsection{Scope of the Item Set}

We adapted a dictionary definition of symptoms for the purpose of this study (32). Symptoms eligible for inclusion in the item set were defined as those described by patients as a "physical or 
psychological disturbance from normal biological function, sensation or appearance (but not the impact or interference with normal activities arising from such disturbances, such as activity limitations, or body image)". In this study our focus was on symptoms which are a consequence of treatment, rather than a marker of the disease itself, although we acknowledge that the distinction between treatment-related and disease-related symptoms is not always clearly delineated. Medically defined changes such as abnormal blood tests or a diagnosis based on clinical investigation rather than patient experience were excluded.

Although only the three disease scenarios mentioned above were included in the development of the item set, the intention was for the item set to be used and adapted for different cancer and TT types.

\subsection{Phase 1}

\subsubsection{Literature reviews}

Systematic reviews of the literature relating to toxicities of TTs for CML, breast cancer, and GIST have been reported elsewhere $(19,33,34)$.

\subsubsection{Patient interviews and focus groups}

In the development of the QLQ-CML24, patients with CML were interviewed and asked to rate the relevance and importance of $\mathrm{HRQOL}$ concerns (including symptom issues) captured from the literature. Full details are reported elsewhere (28).

Interviews were conducted with patients diagnosed with HER2 positive breast cancer or GIST. The numbers of patients interviewed were in accordance with QLG Guidelines (22). Patients who were receiving or had previously received TT for breast cancer or GIST were invited to participate by their clinician. In addition, patients with GIST were recruited for telephone interviews through the GIST UK Support Group website. Finally, a focus group was conducted for each diagnosis in Southampton, 
UK. The focus groups provided an opportunity for patients to collectively review the set of symptoms captured thus far and to consider new symptoms.

In a semi-structured interview, or focus group, patients were asked to consider their experiences while taking $T T$ and to only report, where possible, side-effects they associated with TTs, rather than the cancer itself, other treatments, or other factors such as pre-existing conditions and age.

The interview and focus group schedules are presented as supplementary material (Supplementary material 1).

\subsubsection{HCP Interviews}

As part of the development of the EORTC QLQ-CML24, interviews were conducted with HCPs who treat CML (28).

Interviews with HCPs, with specialist experience in breast cancer or GIST were also carried out at each participating centre. The interviews were carried out in parallel with the patient interviews. HCPs were asked to report side-effects they associated with TTs.

\subsection{Phase 2}

\subsubsection{Selection of symptoms}

The researchers reviewed all symptoms generated from the interviews, focus groups and literature reviews. Symptoms generated by more than one data capture method (literature, interviews (patients and HCPs) or focus groups), and those with a prevalence of at least $5 \%$ of interviews were considered for retention. Symptoms with closely related content were rejected or combined to avoid redundancy.

\subsubsection{Item generation}

Questions included in existing EORTC quality of life questionnaires were firstly reviewed to identify whether they offered a good match to the symptoms identified. The wording of existing EORTC questions was sometimes adapted to adequately cover the symptom under consideration. When 
there was no corresponding item, new symptom questions were constructed. A time frame of "the last week" for recall of symptoms was chosen, for consistency with the usual time frame of validated EORTC items although, for some symptoms, where little change would be expected over a week, the time frame of "the past 4 weeks" was adopted .

\subsubsection{Clinical review and translation}

The item set for breast and GIST patients was sent to six health professionals in the participating centres. Reviewers were asked to consider whether the items were relevant and appropriate for their patients and to consider any important omissions. The CML items also underwent clinical review and translation as part of the development of the EORTC QLQ-CML24.

\subsection{Phase 3: Pilot testing the item set}

A draft item set was pilot tested with a separate group of patients diagnosed with $\mathrm{CML}$, breast cancer, or GIST, and who were receiving or had previously been treated with TT. Patients were asked to complete the EORTC QLQ-C30 and the draft item set, and to rate the incidence, relevance and importance of each symptom from "not at all" to "very much". They were also asked to identify any important omissions from the set and whether any items were upsetting or inappropriate, or difficult to understand. Items reported as confusing, and those displaying overlap with other items were considered for rejection.

\subsubsection{Generation of recommendations for developing item sets}

In order to evaluate the contribution of each method of symptom capture (literature, patients and HCPs) to the provisional and final item set, the number of symptoms captured by each method was compared. This comparison informed recommendations for the optimal practice of generating symptom lists. 


\subsubsection{Ethics}

All procedures were in accordance with the ethical standards of the institutional and/or national research committee and with the 1964 Helsinki Declaration and its later amendments or comparable ethical standards. The study was approved at the lead site (University of Southampton, United Kingdom) by NRES Committee South Central Southampton B (11/SC/0412). All patients gave informed written consent to participate.

\section{Results}

\subsection{Phase 1}

\subsubsection{Literature reviews}

Of the $74 \mathrm{HRQOL}$ issues identified from the CML literature review (34), 45 described symptoms. Forty-one issues were identified from the physical symptom category list (such as swelling, cramps and gastro-intestinal symptoms) and four from the psychosocial category (such as depression and worry).

The breast cancer literature review identified a total of 46 symptoms (33). Diarrhoea and skin rash were the most prevalent symptoms, experienced by $29 \%$ and $22 \%$ of patients overall. Most symptoms $(n=52)$ were experienced by $1 \%$ or less of patients and were predominantly of Grade $1 / 2$ toxicity.

Our review (19) of symptoms experienced during treatment with TTs for GIST identified 64 symptoms covering physical side-effects such as fatigue, nausea, and oedema, as well as psychological symptoms of depression, confusion and concentration problems. Fifty-six (88\%) symptoms were captured from studies reporting side-effects of imatinib and $33(52 \%)$ related to sunitinib. Important differences in the symptom profiles of imatinib and sunitinib were seen in the frequencies of oedema, muscle and joint pains, skin and oral conditions. 


\subsubsection{Interviews and focus groups}

\subsubsection{Patients}

Interviews were conducted with 137 patients receiving treatment for CML (mean age of 56.7 years) in seven hospitals in Germany, Greece, Italy, Iraq and Taiwan (28). Forty-three percent of patients were on treatment with first line imatinib and $46 \%$ were on second-line treatment with second generation TKIs (nilotinib and then dasatinib). About half of the patients (53\%) had been treated for more than five years. An additional 99 patients were recruited through an Italian CML patient advocacy website and invited to comment on the HRQOL issues. Data generated from this sample were used for supportive analysis.

Fifty-three female patients with breast cancer, 47 of whom were currently receiving $\Pi T$ (s) were interviewed across five countries and an additional 5 patients attended a focus group (Table 1). Twenty-seven patients from three countries currently on TT for a GIST were interviewed and a further 5 patients attended a focus group (Table 1).

Table 2 outlines the clinical characteristics (including type of TT) of the patients with breast cancer and GIST.

\subsubsection{Health Care Professionals}

Fifty-nine HCPS from 12 countries treating patients with CML were interviewed as part of the EORTC QLQ-CML24 development (28). Twenty-five HCPs with expertise in treating breast cancer or GIST were also interviewed (Table 3).

\subsubsection{Symptoms}

Forty-five CML-related symptoms were identified in the development of the EORTC QLQ-CML24; 112 symptoms were reported by patients with breast cancer, and 141 by those with GIST.

In the HCP interviews, a total of 72 symptoms were identified for breast cancer and 53 symptoms were identified for GIST. 
Patients described 209 symptoms (Table 4). Of these, 61 were reported within the context of breast cancer, 77 in GIST and 70 in both tumour types. One additional symptom (problems with sweating) was obtained from the CML data (Table 5).

\subsubsection{Contribution of each method to the development of the item list}

Forty-seven symptoms in the draft list were captured by all sources (literature, patients and HCPs). Each source of symptoms gave some unique issues (Table 4) with patients offering the greatest contribution of these: the literature and HCPs identified one unique symptom each (Infections was uniquely captured in the literature and bleeding gums mentioned only by HCPs) while patient interviews identified six unique symptoms (frequent urination, feeling tense, heart palpitations, pale/cold fingers, impaired motivation and sensitivity of the skin to the sun). In addition to infections and bleeding gums, only two other symptoms (painful bowel movements and cough) were not mentioned by patients.

\subsection{Phase 2}

\subsubsection{Selection of symptoms}

Figure 1 outlines the process of reduction of symptoms into the draft item set. This included 74 symptoms, organised in 15 categories (Table 4). With the exception of infection, weight gain and weight loss, which were rated "during the past 4 weeks", all symptoms were scored "during the past week".

\subsection{Phase 3}

\subsubsection{Pilot testing the draft item set}

One hundred and two patients from seven countries completed the draft item set (Supplementary material 2; Table 2.1). Just over half the sample (51\%) had breast cancer, followed by GIST (34\%) and CML (15\%). Patients had experience of treatment with at least one of 10 TTs (Supplementary material 2; Table 2.2), the most common TT was imatinib (41\%) followed by trastuzumab (38\%), and 
$32 \%$ started TT in the last 6 months. Except for two patients, all respondents were currently receiving treatment.

The prevalence of symptoms across all three cancer types and different TTs was low. For 29 symptoms, fewer than $10 \%$ patients rated their severity "quite a bit" or "very much". The two most frequently reported symptoms were lack of energy (45\%) and tiredness (42\%). These symptoms were recognised as relevant and important by over two-thirds of patients (68\% and $69 \%$ respectively).

After a review of patient comments, 13 items were removed, and some adjustments were made to the categories (Table 4). No new symptoms were identified. The remaining 61 items are presented in Table 5 with the disease scenario in which they were reported during Phase 1 interviews, focus groups and literature reviews. Table 5 shows the distribution of symptoms across cancer types; some symptoms were unique to one cancer, for example, heart palpitations and breast cancer (trastuzumab) and red (bloodshot) eyes and GIST (imatinib). The symptoms are organised within categories for convenience, but this does not imply that there is a scale structure.

Eight symptoms (skin rash, sore or painful skin, palpitations, dry eyes, itchy eyes, nose bleeds, other nose problems, dizziness) were not identified within the EORTC QLG Item Library and represent new items and 15 (e.g., skin colour changes, itchy skin, watery eyes) required adaptations of existing EORTC QLG items.

\subsubsection{Contribution of each method to the development of the final item set}

Patients made the greatest contribution to the final symptom set with 58 of the 61 symptoms mentioned by patients during Phase 1 interviews and focus groups, compared with 47 presented by HCPs and 52 symptoms identified in the literature. 


\section{Discussion}

This paper describes the process of identifying and creating a set of symptoms experienced by patients with three different cancers treated with a range of TTs. The well-established QLG methods (22) for item generation were used. Comparison of the source(s) of each item has enabled the formulation of recommendations for developing and using item lists for specific TTs and tumour sites.

\subsection{Creating Item Lists}

In line with the robust EORTC QLG recommendations for questionnaire generation (22), three sources were used to identify potential symptoms for inclusion in the item set and we were able to compare the input from each source. Data were retrieved from interviews with patients and HCPs, patient focus groups and systematic reviews of the literature. Literature reviews were timeconsuming and labour-intensive. None of the symptoms identified only from the literature reviews were included in the final item set. To identify side-effects of new treatments during development, a full systematic review is unlikely to be productive.

Patients' accounts of symptoms offered the greatest contribution to the content of the item set and we therefore recommend, as a minimum, involving patients in the development of symptom lists. Our recommendation to prioritise patient interviews in the development of symptom lists will ensure content validity as well as reduce the resource burden on the development process. This mirrors other work underlining the importance of the patient's voice in the identification of symptoms to be included in PRO measures (26).

During product development, patient experience with a new drug may be limited. The greatest amount of patient-reported data on symptoms associated with a new treatment is likely to be in the case report forms from phase 1 and 2 clinical trials. We recommend consulting these data when an item list is created to be used in a phase 3 clinical trial. 
The EORTC QLG Item Library is a valuable resource when creating item lists (23). It consists of items that have been developed with care to avoid confusing phrasing, and to facilitate translation; the items have all been widely tested and found to be acceptable in a variety of cultures, and all items have already been translated into many languages. Most items (87\%) included in our item set were obtained from the EORTC QLG Item Library, although a small number required slight modification. For eight symptoms not covered by existing items, new questions were developed using a format consistent with existing items. These have now been added to the Item Library. All items included in the set, including the newly created ones, were acceptable to patients during pilot testing which suggests that this method could be replicated for other conditions or treatments. These items will make a valuable contribution to the rapid development of measures to evaluate new treatments across different tumour types, consistent with EORTC QLG strategy (5). The EORTC QLG is currently developing guidelines to assist researchers design new, perhaps trial-specific, symptom questionnaires, during development of new therapies. The symptoms set may also be used to monitor treatment with TTs, for example to document the response to changes in therapy.

\subsection{Recommendations for optimising practice for generating item lists}

The following recommendations for developing an item set are proposed:

1. Identify relevant issues using patient interviews in the target population.

2. Supplement the interview data with a review of clinical reports and preclinical trial data.

3. Search the EORTC QLG Item Library for relevant questions. If new items are required, EORTC QLG guidance should be followed.

\subsection{Using Item Lists}

Current EORTC QLG strategy recommends using additional items from the EORTC QLG Item Library as an "add-on" to supplement the EORTC QLQ-C30 and existing disease-specific measures. This 
strategy aims to enhance sensitivity to the side-effects of new treatments $(23,24)$ and should facilitate the measurement of adverse events of new treatments, and their impact on the common functional health problems reported by patients.

In the context of two of the cancer types investigated in the current study, CML and breast cancer, an item list could be used alongside the EORTC QLQ-C30 and the relevant disease-specific module. In breast cancer, for example, a clinician or researcher could use the EORTC QLQ-C30 with the newlyupdated EORTC QLQ-BR45 (35), and add the symptom items of broken nails and heart palpitations. For GIST, where there is currently no specific module, an item set could be used to record swelling, cramps, eye and skin problems, to complement the EORTC QLQ-C30, with the caveat that the item set provides data only about treatment-related symptoms rather than GIST-specific functioning.

In some cases, an investigator may be concerned with comparing specific symptoms associated with different treatments, rather than the full symptom profile. The symptom set generated in this study is organised into categories to facilitate the generation of focussed symptom lists, for example, to assess gastro-intestinal or skin symptoms.

Item lists could serve as a valuable tool to support clinicians' consultations with patients, enhancing the quality and content of such consultations (36). A set of questions about symptoms could be completed before the patient sees the clinician. This will identify symptoms relevant to the patient to be discussed during the consultation, supporting the delivery of personalised care. Showing patients symptom lists prior to their consultation could open up conversations about rare and unexpected symptoms which might otherwise be overlooked and might serve as an early warning system. Some of the symptoms (e.g., skin colour changes) in the list we generated were not mentioned by HCPs perhaps because untreated, they are not likely to have serious health implications. However, these symptoms can affect patients' HRQOL and compliance with treatment. HCPs are unlikely to have treatments to overcome these symptoms, yet they remain very relevant to patients. Having this information about a list of symptoms that patients believe to be relevant to 
their well-being is critical to open consultations that meet a patient's needs and could inform the development of symptom control treatments.

\subsection{Caveats}

The item set presented is not intended for use in its entirety; not all symptoms are relevant for all disease and treatment scenarios.

Although the item set generated in this study is extensive in its coverage of symptoms, the set is expected to expand to accommodate novel symptoms reported by patients treated with new and different TTs.

It is important to reiterate that item lists do not provide a comprehensive measure of HRQOL. Rather they can supplement existing HRQOL measures.

We do not recommend generating a total score from item lists; each item should be scored separately rather than used to create sub-scale scores.

\subsection{Strengths of the study}

This study used the rigorous methodology of the EORTC QLG (22) which involved different strategies of generating symptoms related to a variety of TTs used in the treatment of three different cancer types. This ensured comprehensive coverage of potential items, and multinational, multilingual development. The study design also lent itself to a comparison of the unique contribution of each method of symptom-capture: literature, patients and HCPs.

\subsection{Limitations of the study}

This study developed an item set that would be useful for symptom reporting by patients receiving TTs. For practical considerations the patient groups were limited to three tumour types, and the therapies included were those in wide use at the time of the study. Additional symptoms may be 
experienced with other tumours or new therapies. However, we have offered recommendations for the creation of bespoke symptom lists specific to other TT types. Although at the outset we defined the scope of what would be considered a symptom, some issues initially selected for inclusion were subsequently rejected as they did not fit the symptom definition, suggesting that there was initial lack of clarity in the application of the symptom definition. Finally, symptoms were only selected if they were perceived by the patient as specifically $T \mathrm{~T}$-induced. The challenge of identifying symptoms that are exclusively treatment-related is widely acknowledged (37) and we relied on patient recall of onset, and whether dose modification led to an improvement in symptoms. We aimed to be inclusive of symptoms rather than rigorous in attributing their cause.

\section{Conclusion}

This study has demonstrated the feasibility of developing a patient-reported assessment of symptoms specific to novel TTs using the robust methods recommended by the EORTC QLG. Our study underlines the central role of patients in the development of PRO measures including item sets. We recommend that investigators and clinicians can select individual symptoms from the Item Library to create bespoke symptom assessments to supplement HRQOL assessment. Such a list would include symptoms expected to change with a treatment, or symptoms which require careful monitoring and management. 
Table 1. Demographic characteristics of GIST and breast cancer patients

\begin{tabular}{|c|c|c|c|c|}
\hline & $\begin{array}{c}\text { Breast cancer } \\
\text { Interviews }(\mathrm{N}=53)\end{array}$ & $\begin{array}{l}\text { Breast cancer } \\
\text { Focus Group } \\
\quad(\mathrm{N}=5)\end{array}$ & $\begin{array}{l}\text { GIST Interviews } \\
(\mathrm{N}=27)\end{array}$ & $\begin{array}{l}\text { GIST Focus } \\
\text { Group }(N=5)\end{array}$ \\
\hline \multicolumn{5}{|l|}{$\begin{array}{l}\text { Patients per country } \\
\mathrm{N}(\%)\end{array}$} \\
\hline UK & $13(25 \%)$ & $5(100 \%)$ & $19(70 \%)$ & $5(100 \%)$ \\
\hline Poland & $7(13 \%)$ & 0 & $5(19 \%)$ & 0 \\
\hline Cyprus & $15(28 \%)$ & 0 & $3(11 \%)$ & 0 \\
\hline France & $13(25 \%)$ & 0 & 0 & 0 \\
\hline Greece & $5(9 \%)$ & 0 & 0 & 0 \\
\hline \multicolumn{5}{|l|}{ Gender } \\
\hline Female & $53(100 \%)$ & $5(100 \%)$ & $13(48 \%)$ & $2(40 \%)$ \\
\hline Male & 0 & 0 & $14(52 \%)$ & $3(60 \%)$ \\
\hline \multicolumn{5}{|l|}{ Age (years) } \\
\hline mean (SD) & $56.15(10.66)$ & $50.80(9.86)$ & $58.4(15.4)$ & $52.6(6.4)$ \\
\hline range & $32-82$ & $38-64$ & $20-85$ & $44-62$ \\
\hline \multicolumn{5}{|l|}{ Education level } \\
\hline Less than compulsory & $2(4 \%)$ & 0 & 0 & 0 \\
\hline $\begin{array}{r}\text { Compulsory school } \\
\text { education }\end{array}$ & $13(25 \%)$ & $3(60 \%)$ & $10(37 \%)$ & $3(60 \%)$ \\
\hline $\begin{array}{l}\text { Post compulsory school } \\
\text { education (college) }\end{array}$ & $22(42 \%)$ & 0 & $5(19 \%)$ & $1(20 \%)$ \\
\hline University & $16(30 \%)$ & $1(20 \%)$ & $12(44 \%)$ & $1(20 \%)$ \\
\hline Unknown & 0 & $1(20 \%)$ & & \\
\hline \multicolumn{5}{|l|}{ Employment status } \\
\hline Full time & $12(23 \%)$ & 0 & $5(19 \%)$ & $2(40 \%)$ \\
\hline Part time & $7(13 \%)$ & $1(20 \%)$ & $4(15 \%)$ & $1(20 \%)$ \\
\hline Homemaker & $8(15 \%)$ & $1(20 \%)$ & $1(4 \%)$ & 0 \\
\hline Retired & $14(26 \%)$ & $1(20 \%)$ & $15(56 \%)$ & $1(20 \%)$ \\
\hline Other $^{1}$ & $12(23 \%)$ & $2(40 \%)$ & $2(7 \%)$ & $1(20 \%)$ \\
\hline \multicolumn{5}{|l|}{ Living situation } \\
\hline Alone & $4(8 \%)$ & $1(20 \%)$ & $2(7 \%)$ & $1(20 \%)$ \\
\hline Partner & $25(47 \%)$ & $4(80 \%)$ & $16(59 \%)$ & $2(40 \%)$ \\
\hline Others & $24(45 \%)$ & 0 & $9(33 \%)$ & $2(40 \%)$ \\
\hline
\end{tabular}

${ }^{1}$ Other employment categories included sick leave, unemployed, and semi-retired 
Table 2 Clinical characteristics of GIST and breast cancer patients

\begin{tabular}{|c|c|c|c|c|}
\hline & $\begin{array}{c}\text { Breast } \\
\text { cancer } \\
\text { Interviews } \\
(\mathrm{N}=53)\end{array}$ & $\begin{array}{l}\text { Breast } \\
\text { cancer } \\
\text { Focus } \\
\text { Group } \\
(\mathrm{N}=5)\end{array}$ & $\begin{array}{c}\text { GIST } \\
\text { Interviews } \\
(\mathrm{N}=27)\end{array}$ & $\begin{array}{l}\text { GIST } \\
\text { Focus } \\
\text { Group } \\
(N=5)\end{array}$ \\
\hline \multicolumn{5}{|l|}{ Disease status } \\
\hline Localised & $32(60 \%)$ & 0 & $10(37 \%)$ & $2(40 \%)$ \\
\hline Metastatic & $20(38 \%)$ & $5(100 \%)$ & $17(63 \%)$ & $3(60 \%)$ \\
\hline Missing & $1(2 \%)$ & 0 & 0 & 0 \\
\hline \multicolumn{5}{|l|}{$\begin{array}{l}\text { Years since initial } \\
\text { diagnosis }\end{array}$} \\
\hline$<5$ & $41(77 \%)$ & $3(60 \%)$ & $14(52 \%)$ & $3(60 \%)$ \\
\hline $5-10$ & $8(15 \%)$ & 0 & $10(37 \%)$ & $2(40 \%)$ \\
\hline $10-15$ & $3(6 \%)$ & $2(40 \%)$ & $2(7 \%)$ & 0 \\
\hline$>15$ & $1(2 \%)$ & 0 & $1(4 \%)$ & 0 \\
\hline \multicolumn{5}{|l|}{ Treatment } \\
\hline Trastuzumab & $45(85 \%)$ & $5(100 \%)$ & & \\
\hline Bevacizumab & $7(13 \%)$ & $1(20 \%)$ & & \\
\hline $\begin{array}{r}\text { Trastuzumab and } \\
\text { Pertuzumab }\end{array}$ & $1(2 \%)$ & 0 & & \\
\hline Imatinib & & & 27 (100\%) & $5(100 \%)$ \\
\hline Sunitinib & & & $9(33 \%)$ & 0 \\
\hline Regorafenib & & & $5(19 \%)$ & 0 \\
\hline \multicolumn{5}{|l|}{ Co-morbidities } \\
\hline None & 42 (79\%) & $5(100 \%)$ & $17(63 \%)$ & $2(40 \%)$ \\
\hline Renal & 0 & 0 & 0 & $1(20 \%)$ \\
\hline Cardiac & $5(9 \%)$ & 0 & $2(7 \%)$ & 0 \\
\hline Respiratory & $1(2 \%)$ & 0 & $1(4 \%)$ & 0 \\
\hline Rheumatic & $1(2 \%)$ & 0 & $3(11 \%)$ & 0 \\
\hline Diabetes & $1(2 \%)$ & 0 & 0 & 0 \\
\hline Other ${ }^{1}$ & $6(11 \%)$ & 0 & $4(15 \%)$ & $2(40 \%)$ \\
\hline \multicolumn{5}{|l|}{$\begin{array}{l}\text { ECOG } \\
\text { Performance } \\
\text { Status }\end{array}$} \\
\hline 0 & 39 (74\%) & $3(60 \%)$ & $20(74 \%)$ & $4(80 \%)$ \\
\hline 1 & $13(24 \%)$ & $1(20 \%)$ & $4(15 \%)$ & $1(20 \%)$ \\
\hline 2 & $1(2 \%)$ & $1(20 \%)$ & $2(7 \%)$ & $2(40 \%)$ \\
\hline Missing & 0 & 0 & $1(4 \%)$ & 0 \\
\hline
\end{tabular}

${ }^{1}$ Other co-morbidities include thyroid problems, hypertension, hip replacement, chronic fatigue syndrome, Parkinson's, depression, eye problems, Miller-Fisher Syndrome, skin problems, lupus and myasthenia. 
Table 3. Recruiting country and specialist discipline of the Breast cancer and GIST HCPs*

\begin{tabular}{|r|c|c|}
\hline & $\begin{array}{c}\text { Breast cancer } \\
(\mathrm{N}=16)\end{array}$ & $\begin{array}{c}\text { GIST } \\
(\mathrm{N}=9)\end{array}$ \\
\hline HCPs per country & $\mathrm{N}(\%)$ & $\mathrm{N}(\%)$ \\
\hline UK & $6(38 \%)$ & $6(67 \%)$ \\
\hline France & $4(25 \%)$ & 0 \\
\hline Poland & $4(25 \%)$ & 0 \\
\hline Cyprus & 0 & $3(33 \%)$ \\
\hline Greece & $2(13 \%)$ & 0 \\
\hline Specialist discipline & & $6(67 \%)$ \\
\hline Medical / Clinical Oncology & $13(81 \%)$ & $2(22 \%)$ \\
\hline Nursing & $3(19 \%)$ & $1(11 \%)$ \\
\hline Palliative Medicine & 0 &
\end{tabular}

*HCP: Health care professionals 
Table 4. Number of items across the symptom categories in the draft and final item set, and contribution made by each method to the item sets

\begin{tabular}{|c|c|c|c|c|}
\hline Symptom Category & Draft & Final & Comment & $\begin{array}{l}\text { Symptoms not captured by all } \\
\text { methods }\end{array}$ \\
\hline Skin & 8 & 6 & $\begin{array}{l}2 \text { redundant items } \\
\text { (sores/ulcers and sun } \\
\text { sensitivity) removed }\end{array}$ & $\begin{array}{l}\text { - Colour change } \\
\text { (literature and patients } \\
\text { only); } \\
\text { - Sores/ulcers (patients } \\
\text { and HCPs only) } \\
\text { - Sun sensitivity (patients } \\
\text { only) }\end{array}$ \\
\hline Swelling & 2 & 2 & & Captured by all methods \\
\hline Musculo-skeletal & 4 & 4 & & $\begin{array}{l}\text { - Bone pain (patients and } \\
\text { HCPs only) } \\
\text { - Back pain (literature } \\
\text { and patients only) }\end{array}$ \\
\hline Mouth & 5 & 5 & & $\begin{array}{ll}\text { - } & \text { Bleeding gums (HCPs } \\
\text { only) }\end{array}$ \\
\hline $\begin{array}{l}\text { Nails } \\
\text { (and hair) }\end{array}$ & $\begin{array}{l}1 \\
\text { (and 3) }\end{array}$ & 1 & $\begin{array}{l}\text { Hair items omitted } \\
\text { because long term } \\
\text { changes, and difficult } \\
\text { to attribute }\end{array}$ & Captured by all methods \\
\hline Heart and breathing & 4 & 4 & $\begin{array}{l}\text { Categories combined; } \\
\text { two items in each }\end{array}$ & $\begin{array}{l}\text { - Heart palpitations } \\
\text { (patients only) } \\
\text { - Chest pain (literature } \\
\text { and HCPs only) }\end{array}$ \\
\hline Fatigue/energy & 3 & 3 & & Captured by all methods \\
\hline Eyes & 7 & 7 & & 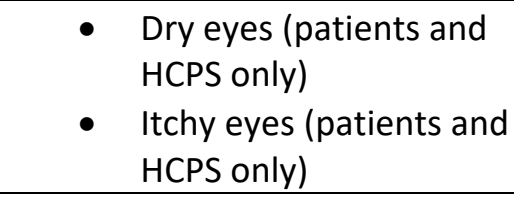 \\
\hline ENT & 4 & 4 & & $\begin{array}{l}\text { - Changes to voice } \\
\text { (literature and patients } \\
\text { only) }\end{array}$ \\
\hline Emotional function & 5 & 5 & $\begin{array}{l}\text { Combined emotional ( } 3 \\
\text { items) and cognitive ( } 2 \\
\text { items) symptoms. }\end{array}$ & $\begin{array}{ll}\text { - } & \text { Concentration } \\
\text { (literature and patients } \\
\text { only) } \\
\text { - } \quad \text { Tense (patients only) } \\
\text { - } \quad \text { Irritability (literature } \\
\text { and patients only) } \\
\end{array}$ \\
\hline Digestion & 13 & 11 & $\begin{array}{l}\text { Combined } 3 \text { groups: } \\
\text { bowels, upper } \\
\text { gastrointestinal tract, } \\
\text { eating and appetite. } \\
2 \text { items redundant/not } \\
\text { relevant including } \\
\text { restricted diet and } \\
\text { change in bowel habits }\end{array}$ & $\begin{array}{ll}\text { - } & \text { Bowel urgency } \\
\text { (patients and HCPs } \\
\text { only) } \\
\text { - } \quad \text { Painful bowel } \\
\text { movements (literature } \\
\text { and HCPs only) } \\
\text { - } \quad \text { Flatulence (literature } \\
\text { and patients only) }\end{array}$ \\
\hline
\end{tabular}




\begin{tabular}{|c|c|c|c|c|}
\hline & & & & $\begin{array}{l}\text { - Indigestion (literature } \\
\text { and patients only) }\end{array}$ \\
\hline General & 15 & 9 & $\begin{array}{l}6 \text { items not relevant or } \\
\text { did not fit time frame } \\
\text { (weight gain, weight } \\
\text { loss, infections, } \\
\text { frequent urination, } \\
\text { fainting, feeling unwell) }\end{array}$ & $\begin{array}{l}\text { - Hot flushes (patients } \\
\text { and HCPs only) } \\
\text { - Infections (literature } \\
\text { only) } \\
\text { - Pale/cold fingers and } \\
\text { toes (patients only) } \\
\text { - Tingling/numbness in } \\
\text { hands or feet } \\
\text { (literature and patients } \\
\text { only) } \\
\text { - Frequent urination } \\
\text { (patients only) } \\
\text { - Motivation (patients } \\
\text { only) }\end{array}$ \\
\hline
\end{tabular}

Notes:

Musculo-skeletal refers to symptoms affecting the joints, bones and muscles.

ENT: symptoms arising in the ears, nose or throat 
Table 5. Symptoms represented in the final item set and reported incidence according to cancer type

\begin{tabular}{|c|c|c|c|c|}
\hline Symptom Category & Symptoms & CML & $\begin{array}{l}\text { Breast } \\
\text { cancer }\end{array}$ & GIST \\
\hline Skin & $\begin{array}{l}\text { Skin colour change } \\
\text { Itchy skin } \\
\text { Skin rash } \\
\text { Dry, flaking or cracked skin } \\
\text { Sore or painful skin } \\
\text { Bruises }\end{array}$ & $\begin{array}{l}v \\
v \\
v \\
v \\
v \\
v\end{array}$ & $\begin{array}{l}v \\
v \\
v \\
v \\
v \\
x\end{array}$ & $\begin{array}{l}\mathbf{v} \\
\mathrm{v} \\
\mathrm{v} \\
\mathrm{v} \\
\mathrm{v} \\
\mathrm{v}\end{array}$ \\
\hline Swelling & $\begin{array}{l}\text { Swelling of legs and ankles } \\
\text { Swelling of face or around the eyes }\end{array}$ & v & $\begin{array}{l}\mathbf{v} \\
\mathrm{x}\end{array}$ & $\begin{array}{l}\mathbf{v} \\
\mathbf{v}\end{array}$ \\
\hline Musculo-skeletal & $\begin{array}{l}\text { Muscle aches, pains or cramps } \\
\text { Aches or pains in joints } \\
\text { Aches or pains in bones } \\
\text { Back pain }\end{array}$ & $\begin{array}{l}\mathrm{v} \\
\mathrm{v} \\
\mathrm{x} \\
\mathrm{X}\end{array}$ & $\begin{array}{l}\mathbf{v} \\
\mathbf{v} \\
\mathbf{v} \\
\mathbf{v}\end{array}$ & $\begin{array}{l}\mathbf{v} \\
\boldsymbol{v} \\
\mathrm{v} \\
\mathrm{v}\end{array}$ \\
\hline Mouth & $\begin{array}{l}\text { Dry mouth } \\
\text { Taste change } \\
\text { Pain or soreness in mouth } \\
\text { Bleeding gums } \\
\end{array}$ & $\begin{array}{l}\mathrm{v} \\
\mathrm{v} \\
\mathrm{v} \\
\mathrm{X}\end{array}$ & $\begin{array}{l}\mathbf{v} \\
v \\
v \\
v\end{array}$ & $\begin{array}{l}\mathbf{v} \\
v \\
v \\
\mathrm{x}\end{array}$ \\
\hline Nails & Nails have broken easily & $x$ & $\mathbf{v}$ & $x$ \\
\hline Heart and breathing & $\begin{array}{l}\text { Heart palpitations } \\
\text { Chest pain } \\
\text { Shortness of breath } \\
\text { Cough }\end{array}$ & $\begin{array}{l}X \\
v \\
v \\
X\end{array}$ & $\begin{array}{l}\mathbf{v} \\
\mathbf{v} \\
\mathbf{v} \\
\mathbf{v}\end{array}$ & $\begin{array}{l}X \\
v \\
v \\
v\end{array}$ \\
\hline Fatigue/ energy & $\begin{array}{l}\text { Tiredness } \\
\text { Weakness } \\
\text { Lack of energy }\end{array}$ & $\begin{array}{l}\mathbf{V} \\
\mathbf{V} \\
\mathbf{V}\end{array}$ & $\begin{array}{l}v \\
v \\
v\end{array}$ & $\begin{array}{l}\boldsymbol{v} \\
\mathbf{v} \\
\mathrm{v}\end{array}$ \\
\hline Eyes & $\begin{array}{l}\text { Watery eyes } \\
\text { Dry eyes } \\
\text { Red (bloodshot) eyes } \\
\text { Itchy eyes } \\
\text { Burning eyes } \\
\text { Sensitivity of eyes to the light } \\
\text { Blurred vision }\end{array}$ & $\begin{array}{l}v \\
x \\
x \\
x \\
v \\
v \\
v\end{array}$ & $\begin{array}{l}\mathbf{v} \\
\boldsymbol{v} \\
\mathrm{X} \\
\mathrm{v} \\
\mathrm{v} \\
\mathrm{v} \\
\mathrm{x}\end{array}$ & $\begin{array}{l}\mathrm{v} \\
\mathrm{v} \\
\mathrm{v} \\
\mathrm{v} \\
\mathrm{v} \\
\mathrm{X} \\
\mathrm{v}\end{array}$ \\
\hline ENT & $\begin{array}{l}\text { Nose bleeds } \\
\text { Other nose problems (smell, sneezing) } \\
\text { Hearing problems } \\
\text { Changes to voice }\end{array}$ & $\begin{array}{l}\mathrm{X} \\
\mathrm{X} \\
\mathrm{V} \\
\mathrm{X} \\
\end{array}$ & $\begin{array}{l}\mathbf{V} \\
\boldsymbol{V} \\
\mathbf{v} \\
\mathbf{X} \\
\end{array}$ & $\begin{array}{l}\boldsymbol{V} \\
\boldsymbol{V} \\
\mathrm{X} \\
\boldsymbol{V}\end{array}$ \\
\hline
\end{tabular}




\begin{tabular}{|c|c|c|c|c|}
\hline & Sore throat & $x$ & $\boldsymbol{v}$ & $\sqrt{ }$ \\
\hline Emotional function & $\begin{array}{l}\text { Depressed } \\
\text { Tense } \\
\text { Irritable } \\
\text { Memory problems } \\
\text { Concentration }\end{array}$ & $\begin{array}{l}\mathbf{v} \\
\boldsymbol{X} \\
\boldsymbol{v} \\
\boldsymbol{v} \\
\boldsymbol{v}\end{array}$ & $\begin{array}{l}\mathbf{V} \\
\boldsymbol{V} \\
\boldsymbol{V} \\
\boldsymbol{V} \\
\boldsymbol{V}\end{array}$ & $\begin{array}{l}v \\
x \\
v \\
v \\
v\end{array}$ \\
\hline Digestion & $\begin{array}{l}\text { Diarrhoea } \\
\text { Constipation } \\
\text { Toilet urgency } \\
\text { Painful bowel movements } \\
\text { Flatulence } \\
\text { Indigestion (heartburn) } \\
\text { Nausea } \\
\text { Vomiting } \\
\text { Appetite loss } \\
\text { Abdominal pains and cramps } \\
\text { Abdominal bloating }\end{array}$ & $\begin{array}{l}\mathbf{v} \\
\mathbf{v} \\
\mathrm{X} \\
\mathrm{X} \\
\mathrm{X} \\
\mathrm{v} \\
\mathrm{v} \\
\mathrm{X} \\
\mathrm{v} \\
\mathrm{v} \\
\mathrm{X}\end{array}$ & $\begin{array}{l}v \\
v \\
x \\
v \\
v \\
v \\
v \\
v \\
v \\
v \\
v\end{array}$ & $\begin{array}{l}\text { v } \\
\text { v } \\
v \\
v \\
v \\
v \\
v \\
v \\
v \\
v \\
v\end{array}$ \\
\hline General & $\begin{array}{l}\text { Fevers or chills } \\
\text { Hot flushes } \\
\text { Excessive sweating } \\
\text { Headaches } \\
\text { Tingling or numbness in hands or feet } \\
\text { Pale or cold fingers or toes } \\
\text { Feeling unwell } \\
\text { Dizziness } \\
\text { Trouble sleeping }\end{array}$ & $\begin{array}{l}v \\
X \\
v \\
v \\
X \\
X \\
X \\
v \\
v\end{array}$ & $\begin{array}{l}\text { v } \\
v \\
X \\
v \\
v \\
v \\
v \\
v \\
v\end{array}$ & $\begin{array}{l}\text { v } \\
v \\
X \\
v \\
v \\
v \\
v \\
v \\
v\end{array}$ \\
\hline
\end{tabular}

Note. Symptoms are scored according to whether they had been experienced within the past week $\mathrm{V}=$ present $\mathrm{X}=\mathrm{absent}$ 
Identified from the literature, interviews and focus groups

\section{Symptoms}<smiles>C1CCCCC1</smiles>

148 Symptoms<smiles>C1CC2CCCC2C1</smiles>

82 Symptoms<smiles>C1CCCCC1</smiles>

Draft Set

74 Symptoms<smiles>C1CCCCC1</smiles>

Final Set

61 Symptoms
60 Symptoms similar in content

1 Not TT-related

59 Low relevance 13 Similar in content 1 Lacks specificity 1 Does not fit symptom definition

Clinical review

6 Do not fit symptom definition

2 Similar in content

9 Not relevant within the time frame (i.e., long-term change) 4 Similar in content 3 Difficult to attribute to TT 


\section{References}

1. US Food and Drug Administration: Guidance for industry: Patient-reported outcome measures-Use in medical product development to support labeling claims.

2. Basch E. Patient-Reported Outcomes - Harnessing Patients' Voices to Improve Clinical Care. New England Journal of Medicine. 2017;376(2):105-8.

3. Kluetz PG, Slagle A, Papadopoulos EJ, Johnson LL, Donoghue M, Kwitkowski VE, et al. Focusing on Core Patient-Reported Outcomes in Cancer Clinical Trials: Symptomatic Adverse Events, Physical Function, and Disease-Related Symptoms. Clinical Cancer Research. 2016;22(7):1553-8.

4. European Medicines Agency Committee for Medicinal Products for Human Use (CHMP) Appendix 2 to the guideline

on the evaluation of anticancer medicinal products in man. The use of patient-reported outcome (PRO) measures in

oncology studies. Canary Wharf, London.: EMA; 2016 [Available from:

https://www.ema.europa.eu/en/appendix-2-guideline-evaluation-anticancer-medicinal-productsman-use-patient-reported-outcome-pro.

5. Groenvold M, Aaronson NK, Darlington A-SE, Fitzsimmons D, Greimel E, Holzner B, et al. Focusing on Core Patient-Reported Outcomes in Cancer Clinical Trials-Letter. Clinical Cancer Research. 2016;22(22):5617-.

6. Bottomley A, Reijneveld JC, Koller M, Flechtner H, Tomaszewski KA, Greimel E, et al. Current state of quality of life and patient-reported outcomes research. European Journal of Cancer. 2019;121:55-63.

7. Judson TJ, Bennett AV, Rogak LJ, Sit L, Barz A, Kris MG, et al. Feasibility of long-term patient self-reporting of toxicities from home via the Internet during routine chemotherapy. J Clin Oncol. 2013;31(20):2580-5.

8. Warrington L, Absolom K, Holch P, Gibson A, Clayton B, Velikova G. Online tool for monitoring adverse events in patients with cancer during treatment (eRAPID): field testing in a clinical setting. BMJ Open. 2019;9(1):e025185.

9. Snyder CF, Blackford AL, Wolff AC, Carducci MA, Herman JM, Wu AW, et al. Feasibility and value of PatientViewpoint: a web system for patient-reported outcomes assessment in clinical practice. Psychooncology. 2013;22(4):895-901.

10. Basch E, Deal AM, Kris MG, Scher HI, Hudis CA, Sabbatini $P$, et al. Symptom Monitoring With Patient-Reported Outcomes During Routine Cancer Treatment: A Randomized Controlled Trial. J Clin Oncol. 2016;34(6):557-65.

11. http://outcomes.cancer.gov/tools/pro-ctcae.html.

12. Petersen MA, Aaronson NK, Arraras JI, Chie W-C, Conroy T, Costantini A, et al. The EORTC CAT Core-The computer adaptive version of the EORTC QLQ-C30 questionnaire. European Journal of Cancer. 2018;100:8-16.

13. Cella D GR, Lai JS, Choi S. . The future of outcomes measurement: item banking, tailored short-forms, and computerized adaptive assessment. . Quality of Life Research. 2007;16(Suppl 1):133-41.

14. de Wit M, Hajos T. Health-Related Quality of Life. In: Gellman MD, Turner JR, editors. Encyclopedia of Behavioral Medicine. New York, NY: Springer New York; 2013. p. 929-31.

15. Vogel CL, Cobleigh MA, Tripathy D, Gutheil JC, Harris LN, Fehrenbacher L, et al. First-line Herceptin monotherapy in metastatic breast cancer. Oncology. 2001;61 Suppl 2:37-42.

16. Druker BJ, Sawyers CL, Kantarjian H, Resta DJ, Reese SF, Ford JM, et al. Activity of a specific inhibitor of the BCR-ABL tyrosine kinase in the blast crisis of chronic myeloid leukemia and acute lymphoblastic leukemia with the Philadelphia chromosome. The New England journal of medicine. 2001;344(14):1038-42. 
17. Joensuu H, Roberts PJ, Sarlomo-Rikala M, Andersson LC, Tervahartiala P, Tuveson D, et al. Effect of the tyrosine kinase inhibitor STI571 in a patient with a metastatic gastrointestinal stromal tumor. The New England journal of medicine. 2001;344(14):1052-6.

18. Demetri GD, von Mehren M, Blanke CD, Van den Abbeele AD, Eisenberg B, Roberts PJ, et al. Efficacy and safety of imatinib mesylate in advanced gastrointestinal stromal tumors. The New England journal of medicine. 2002;347(7):472-80.

19. Sodergren SC, White A, Efficace F, Sprangers M, Fitzsimmons D, Bottomley A, et al. Systematic review of the side effects associated with tyrosine kinase inhibitors used in the treatment of gastrointestinal stromal tumours on behalf of the EORTC Quality of Life Group. Critical Reviews in Oncology/Hematology. 2014;91(1):35-46.

20. Guérin A, Chen L, lonescu-Ittu R, Marynchenko M, Nitulescu R, Hiscock R, et al. Impact of low-grade adverse events on health-related quality of life in adult patients receiving imatinib or nilotinib for newly diagnosed Philadelphia chromosome positive chronic myelogenous leukemia in chronic phase. Current Medical Research and Opinion. 2014;30(11):2317-28.

21. Efficace F, Rosti G, Aaronson N, Cottone F, Angelucci E, Molica S, et al. Patient- versus physician reporting of symptoms and health status in chronic myeloid leukemia. Haematologica. 2014;99(4):788-93.

22. Johnson CD AN, Blazeby J et al. . EORTC Quality of Life Group: guidelines for developing questionnaire modules. 2011.

23. Kuliś D BA, Whittaker C, van de Poll-Franse LV, Darlington A, Holzner B, Koller M, Reijneveld JC, Tomaszewski K, Grønvold M, on behalf of the EORTC Quality of Life Group. , editor The Use of the EORTC Item Library to Supplement EORTC Quality of Life Instruments. . ISPOR 20th Annual European Congress; November 2017; Glasgow, UK: Value in Health

24. Vachalec S BK, Bottomley A, Blazeby J, Flechtner H, Ruyskart P. . EORTC Item Bank Guidelines. Brussels: EORTC Publications; 2001.

25. Mouillet G, Fritzsch J, Paget-Bailly S, Pozet A, Es-Saad I, Meurisse A, et al. Health-related quality of life assessment for patients with advanced or metastatic renal cell carcinoma treated with a tyrosine kinase inhibitor using electronic patient-reported outcomes in daily clinical practice (QUANARIE trial): study protocol. Health and Quality of Life Outcomes. 2019;17(1):25.

26. Bell JA, Galaznik A, Pompilus F, Strzok S, Bejar R, Scipione F, et al. A pragmatic patientreported outcome strategy for rare disease clinical trials: application of the EORTC item library to myelodysplastic syndromes, chronic myelomonocytic leukemia, and acute myeloid leukemia. Journal of Patient-Reported Outcomes. 2019;3(1):35.

27. Bower H, Bjorkholm M, Dickman PW, Hoglund M, Lambert PC, Andersson TM. Life Expectancy of Patients With Chronic Myeloid Leukemia Approaches the Life Expectancy of the General Population. J Clin Oncol. 2016;34(24):2851-7.

28. Efficace F, Baccarani M, Breccia M, Saussele S, Abel G, Caocci G, et al. International development of an EORTC questionnaire for assessing health-related quality of life in chronic myeloid leukemia patients: the EORTC QLQ-CML24. Quality of Life Research. 2014;23(3):825-36.

29. Milanezi F CS, Schmitt FC. EGFR/HER2 in breast cancer: a biological approach for molecular diagnosis and therapy. . Expert Rev Mol Diagn 2008;8:417-34. .

30. Baar J. Biological therapy of breast cancer: recent clinical applications. . Curr Opin Investig Drugs. 2007;8:987-95.

31. Verweij J CP, Zalcberg J, LeCesne A, Reichardt P, Blay JY, Issels R, van Oosterom A, Hogendoorn PC, Van Glabbeke M, Bertulli R, Judson I. . Progression-free survival in gastrointestinal stromal tumours with high-dose imatinib: randomised trial. Lancet. 2004;364(9440):1127-34.

32. Springfield (MA): Merriam-Webster I. Webster's third new international dictionary of the English language, unabridged.2002.

33. Sodergren SC, Copson E, White A, Efficace F, Sprangers M, Fitzsimmons D, et al. Systematic Review of the Side Effects Associated With Anti-HER2-Targeted Therapies Used in the Treatment of Breast Cancer, on Behalf of the EORTC Quality of Life Group. Targeted Oncology. 2016;11(3):277-92. 
34. Efficace F, Cocks K, Breccia M, Sprangers M, Meyers CA, Vignetti M, et al. Time for a new era in the evaluation of targeted therapies for patients with chronic myeloid leukemia: Inclusion of quality of life and other patient-reported outcomes. Critical Reviews in Oncology/Hematology. 2012;81(2):123-35.

35. Bjelic-Radisic V, Cardoso F, Cameron D, Brain E, Kuljanic K, da Costa RA, et al. An international update of the EORTC questionnaire for assessing quality of life in breast cancer patients: EORTC QLQ-BR45<sup>\&\#x2730;</sup>. Annals of Oncology. 2020;31(2):283-8.

36. Velikova G, Booth L, Smith AB, Brown PM, Lynch P, Brown JM, et al. Measuring Quality of Life in Routine Oncology Practice Improves Communication and Patient Well-Being: A Randomized Controlled Trial. Journal of Clinical Oncology. 2004;22(4):714-24.

37. Kluetz PG, Chingos DT, Basch EM, Mitchell SA. Patient-Reported Outcomes in Cancer Clinical Trials: Measuring Symptomatic Adverse Events With the National Cancer Institute's PatientReported Outcomes Version of the Common Terminology Criteria for Adverse Events (PRO-CTCAE). American Society of Clinical Oncology Educational Book. 2016(36):67-73. 